\title{
Teaching the principles of safe prescribing to a mixed profession postgraduate cohort: program development
}

This article was published in the following Dove Press journal: Journal of Multidisciplinary Healthcare

\section{Lynda M Cardiff' \\ Elaine PM Lum' \\ Charles Mitchell' \\ Lisa M Nissen' \\ Marea P Patounas \\ Liza-Jane McBride ${ }^{2}$}

'Pharmacy Discipline, School of Clinical Sciences, Queensland University of Technology, Brisbane, QLD, Australia; ${ }^{2}$ Allied Health Professions' Office of Queensland, Clinical Excellence Division, Queensland Health, Brisbane, QLD, Australia
Correspondence: Lynda M Cardiff School of Clinical Sciences, Queensland University of Technology, Level 9, Q Block, George Street, Brisbane, QLD, Australia

Tel +6I 410 II8 I38

Email lynda.cardiff@qut.edu.au
Background: Prescribing medicines is a complex task. A robust prerequisite curriculum that enables the efficient and consistent training of safe and effective prescribers is important. Despite differing prescribing contexts and professional attributes, the core elements of safe and effective prescribing relevant to all prescribers can be identified. This article describes the development process and content of a training program for safe prescribing, which was designed for a mixed cohort of allied health professionals in Queensland, Australia.

Methods: The allied health prescribing training program was designed to align with national standards for prescribing and competencies for safe prescribing. International training programs, for nonmedical prescribing, were examined to inform the program development. Content was delivered by experienced prescribers from a range of professions. The inaugural cohort was surveyed before and after training to ascertain their confidence to prescribe.

Results: A training program for allied health prescribers was developed and delivered to enable the implementation of a state-sponsored research trial in Queensland public facilities. The program consisted of two modules (the second of which is described in this article) complemented by a mandatory period of supervised workplace learning. Remote blended learning, comprising online prerecorded lectures, self-directed learning, teleconference seminars, and a 2-day oncampus intensive residential, was used to deliver content. A total of 19 allied health professionals (12 physiotherapists and 7 pharmacists) completed the program that equipped them to begin a prescribing trial within their specific practice settings. Post module completion, $90 \%$ of the cohort felt confident to prescribe for patients in their practice area.

Conclusion: Program development and delivery were challenging, requiring attention to both the needs of each profession and those of the individual practitioner who was required to apply generic prescribing principles to their specific practice setting. Further refinement of content, delivery, assessment, and resource allocation is required for future cohorts.

Keywords: allied health, nonmedical prescribing, training, education, curriculum.

\section{Plain language summary}

An increasing number of health professionals are authorized to prescribe medicines. Prescribing is a complex task that requires a detailed understanding of both the medicines to be prescribed and the diseases they treat. It is important that all health professionals who prescribe medicines are adequately trained to do so safely and effectively.

This article describes the development and content of a teaching program designed to teach a group of pharmacists and physiotherapists to prescribe medicines. To the best of our knowledge, this is the first such program developed in Australia. The program consisted of two teaching modules provided to students using a variety of methods, including lectures viewed online and a limited amount of face-to-face teaching. The second module, the focus of this article, 
was provided by experienced prescribers who taught students the principles of safe prescribing, the legal requirements to prescribe, the principles of communicating with patients about medicines, and the risk of error when prescribing. After completing the module, students worked under the supervision of an authorized prescriber to complete a period of 120 hours of workplace-based training.

We found that after completing the program, $90 \%$ of students felt confident to prescribe medicines for the patients they will likely treat. The period of supervised learning appeared important, with more than $70 \%$ of students feeling that this period had contributed to their prescribing confidence.

The program was challenging to develop and deliver. Improvements to the program for future cohorts may include providing students more direction about their supervised learning and improving the way we assess prescribing ability.

\section{Introduction}

Prescribing is a complex task, largely undertaken by the medical profession. In recent years, several additional health professions have included prescribing in their recognized scope of practice, either as an expansion or extension to the existing scope. ${ }^{1}$ In Australia, key motivators for the development of new models of care involving the prescription of medicines include the need to improve timely access to medicines and workforce challenges related to the number and distribution of prescribers. ${ }^{2}$ Prescribing by nonmedical professionals has been shown to be safe and acceptable to stakeholders. $^{3-5}$ In support of these changes to the prescribing workforce and consistent with medical literature, the development of specific training and assessment, designed with a clear focus on the essential elements of safe and effective prescribing, is critical to enable the efficient and effective training of prescribers ${ }^{6-11}$ and ensure patient safety.

A limited number of nonmedical professions have prescribing rights in Australia, including dentists, nurse practitioners, optometrists, paramedics and appropriately endorsed midwives, podiatrists and podiatric surgeons. Current legislation prevents pharmacists and physiotherapists from prescribing medicines, although pharmacists are authorized to prescribe medicines that are available without a prescription.

In 2014, the Queensland University of Technology (QUT) was engaged by the Queensland Department of Health, Allied Health Professions' Office of Queensland (AHPOQ), Clinical Excellence Division, to create a suitable multiprofession training program for physiotherapists and pharmacists who were selected to undertake state-sponsored prescribing research conducted in public hospitals and other facilities. The training program was required to align with the national standards for prescribing, ${ }^{12}$ to be informed by recognized core competencies for safe prescribing, ${ }^{13}$ and to equip allied health professionals to prescribe under the approved research protocol. $^{14}$

This article describes the development and content of the program and the perceptions of the inaugural cohort of Australia's first multiprofession allied health prescribing training program.

\section{Methods}

Development of the training program commenced with a review of nonmedical prescribing programs offered by universities internationally, to compare and contrast prerequisites, program structure, teaching and learning methods, assessment methods, and program duration.

At that time, it appeared that most prescribing programs were designed to teach single profession groups, with the exception of Robert Gordon University's Non-Medical Prescribing program, which included two or more professional groups, ${ }^{15}$ and Keele University's prescribing studies, which included nonmedical professionals (currently, this program appears to be titled Independent \& Supplementary Prescribing for Allied Health Professionals). ${ }^{16}$ For many programs, a prerequisite for enrollment was current clinical, pharmacological, and pharmaceutical knowledge relevant to the intended area of practice.

Program information in published literature ${ }^{17}$ or available on public websites from the following universities was included in the mapping exercise: University of Auckland and University of Otago, New Zealand: Postgraduate Certificate in Clinical Pharmacy in Prescribing (University of Auckland) and Postgraduate Certificate in Pharmacist Prescribing (University of Otago); ${ }^{18,19}$ Robert Gordon University, UK: Pharmacist Independent Prescribing program; ${ }^{20}$ and Keele University, UK: Certificate in Independent Prescribing. ${ }^{21}$ These programs were selected as they appeared to be designed to upskill pharmacists, which comprised approximately half of the cohort when the program was developed. At the time, no programs designed to specifically prepare physiotherapists, the remainder of the cohort, for prescribing were found.

Informed by the mapping exercise, the development of the program addressed the needs of a mixed cohort of professionals (physiotherapists and pharmacists) and was designed to prepare participants to undertake prescribing within the bounds of a research trial, sponsored by AHPOQ. Pharmacists/ physiotherapists who successfully completed the program were awarded a certificate of completion. The design of the program was undertaken within the following constraints:

- The cohort was based in geographically dispersed locations and working across diverse health care settings; 
- Training was to be delivered out of working hours to avoid disruption to clinical workload;

- The two-module training program was to be completed within a year. Each module was to be taught over 13 weeks;

- The practical learning (learning in practice [LIP]) was to be undertaken after successful completion of the two formal teaching modules; and

- Funding was available for one on-campus residential of two days' duration approximately half-way through the lecture series of the second module (Module 2).

The content and delivery of Module 1, Introduction to Clinical Therapeutics for Prescribers, was adapted from the postgraduate nurse practitioner program administered by the Discipline of Pharmacy, QUT; remodeled to specifically address the needs of physiotherapists; and coordinated by two part-time academics.

The content and structure of Module 2, Prescribing and Quality Use of Medicines, designed for both physiotherapists and pharmacists, was developed by two part-time program developers with experience in professional education of clinicians, prescribing competencies, clinical competencies, and assessment practices (total of 0.8 full-time equivalent) over 5 months. Module 2 development included preparation of lecture topics; weekly activities; program guide for the cohort; the content, structure, and delivery of the 2-day on-campus intensive residential and the selection of; and liaison with expert prescribers to deliver lectures. The LIP component of the module required each allied health professional to undertake a total of 120 hours of practicebased learning relevant to prescribing, supervised by a local designated medical practitioner (DMP). Both summative and formative assessments were required during this period. An information and guidance package was developed to support this process. Program developers also assisted in the assessment framework and content and the requirements for the prescribing portfolio. Module 2 was also coordinated by two part-time academics.

The cohort was surveyed immediately before and after the completion of Module 2 to explore their understanding of, and confidence in, safe prescribing. Cohort feedback regarding the 2-day on-campus intensive residential and the LIP component was also sought.

\section{Results}

The allied health prescribing training program was developed during 2014. Training commenced that year and continued into 2015 .

\section{Program structure}

Blended modalities of teaching and learning were used to deliver the two modules, incorporating online learning, regular 2-hour teleconference seminars, a 2-day on campus intensive residential, and a period of practical, supervised learning.

Module 1 provided an understanding of basic pharmacology and pharmacotherapeutics taught over 13 weeks online and through group teleconferences. Lecture topics included an introduction to medicines, pharmacodynamics, pharmacokinetics, drug interactions, general therapeutics, and the effect of medicines on body systems. Exemptions from Module 1 were provided for those who had successfully completed a Bachelor of Pharmacy degree or an appropriate postgraduate qualification that included pharmacology and pharmacotherapeutics.

Module 2 focused on the quality use of medicines and safe and effective prescribing. The module was taught over 13 weeks, online and through group teleconferences. Students and staff were able to meet during a 2-day on-campus intensive residential. Module content was tailored to emphasize core prescribing knowledge and skills, the application of which to specific clinical situations was demonstrated in weekly activities, teleconference group discussions, and the residential. Module 2 was augmented by the LIP, supervised by the DMP and undertaken subsequent to the completion of the module.

The remainder of this article focuses on Module 2, as it was the first such module offered in Australia.

\section{Module 2 outline}

Program content was designed to highlight accepted principles of safe prescribing identified as relevant to all prescribers. It was not feasible to devise content specifically relevant to the context of each prescriber. Consequently, the application of general prescribing principles to the specific context in which prescribing would be undertaken formed an integral part of the learning process. Owing to the different preexisting skill set of each profession, self-regulatory skills were required to enable each pharmacist/physiotherapist to identify their specific required learning and take steps to improve practice areas relevant to prescribing. Interprofessional differences and the diversity of prescribing contexts also challenged the program developers who attempted to provide authentic teaching and assessment material for the cohort.

The formal teaching component of Module 2 consisted of 11 prerecorded lectures of 1-2 hours duration each (total 16 hours), 22 supporting activities (total 30 hours), five group 
teleconferences (9 hours), and a mandatory 2-day on-campus intensive residential, which included both integrated and concurrent sessions for physiotherapists and pharmacists. The estimated weekly time commitment ranged from 2 to 6.5 hours, depending on the scheduled activities. The weekly schedule for Module 2 is shown in Table 1. A period of 4 weeks with no required activities was scheduled after Week 9 due to the Christmas/New Year period. The program recommenced in January with week 10 of the schedule. In addition, following completion of the 13-week module, 120 hours of LIP were required to be undertaken in the workplace, supervised by the DMP.

Lectures were provided by senior clinicians from a range of professions with expertise in prescribing. All lectures were prerecorded using voice-over technology. Academic staff cofacilitated teleconference seminars to address issues arising from the lectures and to further discuss lecture content as required. Proprietary information technology, provided by the university, was used to assist delivery of module content.

The 2-day on-campus intensive residential was facilitated by guest lecturers, program developers, and coordinators, all of whom were clinicians. The residential provided the only opportunity for face-to-face meetings between program staff and the cohort and enabled a deeper understanding of each physiotherapist/pharmacist's prescribing setting. As such, the residential was a crucial component of the program. Dedicated learning facilities, including the QUT Clinical Simulation Centre (equipped with "mock ward" facilities and trained staff to assist with role play activities and coordination of the sessions), were used during the residential. The design and format of the residential were intended to provide a safe learning environment for participants to practice new prescribing skills, receive feedback from experienced clinicians, and benefit from the interprofessional learning that comes with a mixed professional cohort. Topics covered in the practical sessions included ethics and case management, communication skills, medication errors, and prescribing collaboratively.

\section{LIP}

The required LIP component was designed to enhance learning in each student's clinical environment and was undertaken after successful completion of the formal learning provided by Module 2. Prior to commencement of the LIP, each physiotherapist and pharmacist completed a learning plan specific to their intended scope of practice as a prescriber, including identification of personal practice areas that required improvement. The learning plan was discussed with and approved by the DMP, prior to submission to the QUT program coordinators.

During the LIP, prescribing was not permitted according to current legislation, although the cohort was encouraged to complete the initial stages of the prescribing process, including patient assessment and clinical decision-making, and to discuss their therapeutic decisions with the DMP who provided formative assessment and feedback. Mock prescription templates were provided to allow practice completion of legal and unambiguous prescriptions, with completed mock prescriptions submitted to QUT as part of a comprehensive LIP portfolio.

Each DMP supervised 120 hours of prescribing practice and facilitated learning according to the agreed and approved learning plan. DMPs were able to delegate some aspects of supervision to other health professionals within their clinical team but were responsible for direct observation of prescribing practice as part of the formative and summative assessment process.

\section{Cohort}

Module 2 was completed by 19 health professionals (12 physiotherapists and 7 pharmacists). A total of 24 health professionals were initially enrolled in the program. Reasons for failure to complete the program included issues identified with the implementation of the prescribing model in the work environment, difficulty completing the required LIP, interstate move, and failure to pass required assessment. Most of the physiotherapists were working in emergency departments or outpatient orthopedic and/or neurosurgery screening clinics. Pharmacists worked in a mix of settings including acute medical admissions units, emergency departments, specialized hospitals, and community-based units. Across the cohort, the average number of years registered was 16 years (range, 5-33 years) and the average number of years of experience in the hospital setting was 11 years (range, $<1$ to 30 years).

\section{Assessment}

Effective assessment of prescribing knowledge and skills is challenging. General principles of assessment suggest that multiple assessment methods, used in a number of applicable contexts and ideally including an indication of practitioner performance in the workplace, are required to provide a realistic picture of ability. ${ }^{22,23}$ Assessment in the context of the present cohort was challenged by the geographical location of students (and the consequent inability of university staff to personally assess performance in the workplace) and the variable contexts in which prescribing would ultimately occur. 
Table I Module 2 content

\begin{tabular}{|c|c|c|c|}
\hline Week & Lecture topic & Required activities & $\begin{array}{l}\text { Teleconference } \\
\text { seminars }\end{array}$ \\
\hline I & Clinical governance & $\begin{array}{l}\text { - } \text { Practice reflection } \\
\text { - Online module (National Prescribing Service) }\end{array}$ & $\begin{array}{l}\text { Introduction } \\
\text { Information } \\
\text { technology, } \\
\text { program schedule }\end{array}$ \\
\hline 2 & What is prescribing? & $\begin{array}{l}\text { - Review video } \\
\text { - Self-assessment against national prescribing competencies }\end{array}$ & \\
\hline 3 & Prescribing and medical error & $\begin{array}{l}\text { - Review Institute for Healthcare Improvement (IHI) case } \\
\text { (medical error) } \\
\text { - Online module (National Prescribing Service) }\end{array}$ & \\
\hline 4 & Patient information gathering & $\begin{array}{l}\text { - Reflection - potential barriers to communication } \\
\text { - Active listening }\end{array}$ & \\
\hline 5 & Adherence & $\begin{array}{l}\text { - Ceasing medications } \\
\text { - Motivational interviewing }\end{array}$ & $\begin{array}{l}\text { Discussion } \\
\text { Active listening }\end{array}$ \\
\hline 6 & Clinical decision-making & $\begin{array}{l}\text { - Shared decision-making } \\
\text { - Online module (National Prescribing Service) }\end{array}$ & \\
\hline \multicolumn{4}{|c|}{ On-campus intensive residential ( 14 hours) } \\
\hline 7 & $\begin{array}{l}\text { Prescribing and working } \\
\text { collaboratively }\end{array}$ & $\begin{array}{l}\text { - Reflection } \\
\text { - Clinical handover standard }\end{array}$ & $\begin{array}{l}\text { Case-based } \\
\text { Prescribing } \\
\text { collaboratively }\end{array}$ \\
\hline 8 & $\begin{array}{l}\text { Adverse drug reaction reporting, } \\
\text { complementary medicines }\end{array}$ & $\begin{array}{l}\text { - Cultural awareness } \\
\text { - Online module (National Prescribing Service) }\end{array}$ & \\
\hline 9 & Nil & - Best possible medication history & \\
\hline 10 & $\begin{array}{l}\text { Professional, legal, ethical } \\
\text { requirements }\end{array}$ & - Challenging communication & \\
\hline II & Monitoring and review & - Case-based scenario & $\begin{array}{l}\text { Discussion } \\
\text { Areas of concern }\end{array}$ \\
\hline 12 & Prescribing pitfalls & $\begin{array}{l}\text { - Online modules (National Prescribing Service) } \\
\text { - Completion of a prescription }\end{array}$ & \\
\hline 13 & Module summary and questions & - Avoiding potential bias in prescribing practice & $\begin{array}{l}\text { Prescribing } \\
\text { collaboratively } \\
\text { Summary and } \\
\text { questions }\end{array}$ \\
\hline
\end{tabular}

Assessment items included a written submission describing the clinical governance structure of the workplace and changes required to implement prescribing, an evaluation of the developed prescribing LIP portfolio and its illustration of the learning that had occurred during the LIP, a multiplechoice examination, submission of at least four cases illustrating the essential elements of the prescribing process (gathering of patient-related information, clinical decisionmaking, communicating the prescribing decision to both the patient/carer and other health professionals, and monitoring/ review of prescribed medicine), a clinical case examination conducted through online resources using trained actors, evidence of completion of all weekly activities, and successful completion of the LIP component.

During the LIP, key competencies were assessed formatively by the DMP with appropriate feedback provided to the physiotherapist or pharmacist. All key competencies, as defined by Lum et al, ${ }^{13}$ were assessed summatively, at least once, by the DMP.

\section{Student support}

The cohort was supported by two part-time program coordinators who were the first point of contact and responsible for regular communication, management of the online learning platform and associated information systems, and coordination of teleconference seminars and assessments.

\section{Perceptions of the cohort}

Surveys were conducted to investigate student confidence to complete prescribing tasks before and after module completion. The design of these pre/post surveys did not support formal analysis using inferential statistics. However, responses indicated a general trend toward improved confidence to undertake prescribing tasks as a result of the LIP, the residential and the module itself.

Response rates for the surveys conducted immediately before and after Module 2 were $77 \%$ and $91 \%$, respectively. After module completion, all respondents either agreed or strongly agreed that they had a good understanding of safe 
and effective prescribing processes, while $90 \%$ felt confident to prescribe safely for patients in their selected area of practice (Figure 1).

The cohort's level of confidence to perform selected tasks before and after the 2-day on-campus intensive residential is shown in Table 2. Response rates for pre/post residential surveys were $96 \%$ and $92 \%$ respectively. The difference in scores indicated that all respondents gained confidence from attending the residential.
A post-program survey undertaken at the completion of the LIP component of the program (response rate $74 \%$ ) indicated that the majority of respondents felt adequately prepared to undertake the LIP, supported during the LIP and that the LIP was useful to clarify and provide confidence regarding the future prescribing role (Table 3 ). Free-text comments indicated that additional clarity regarding the logistics of completing this part of the program would be useful. The extended time taken to complete the required hours of LIP

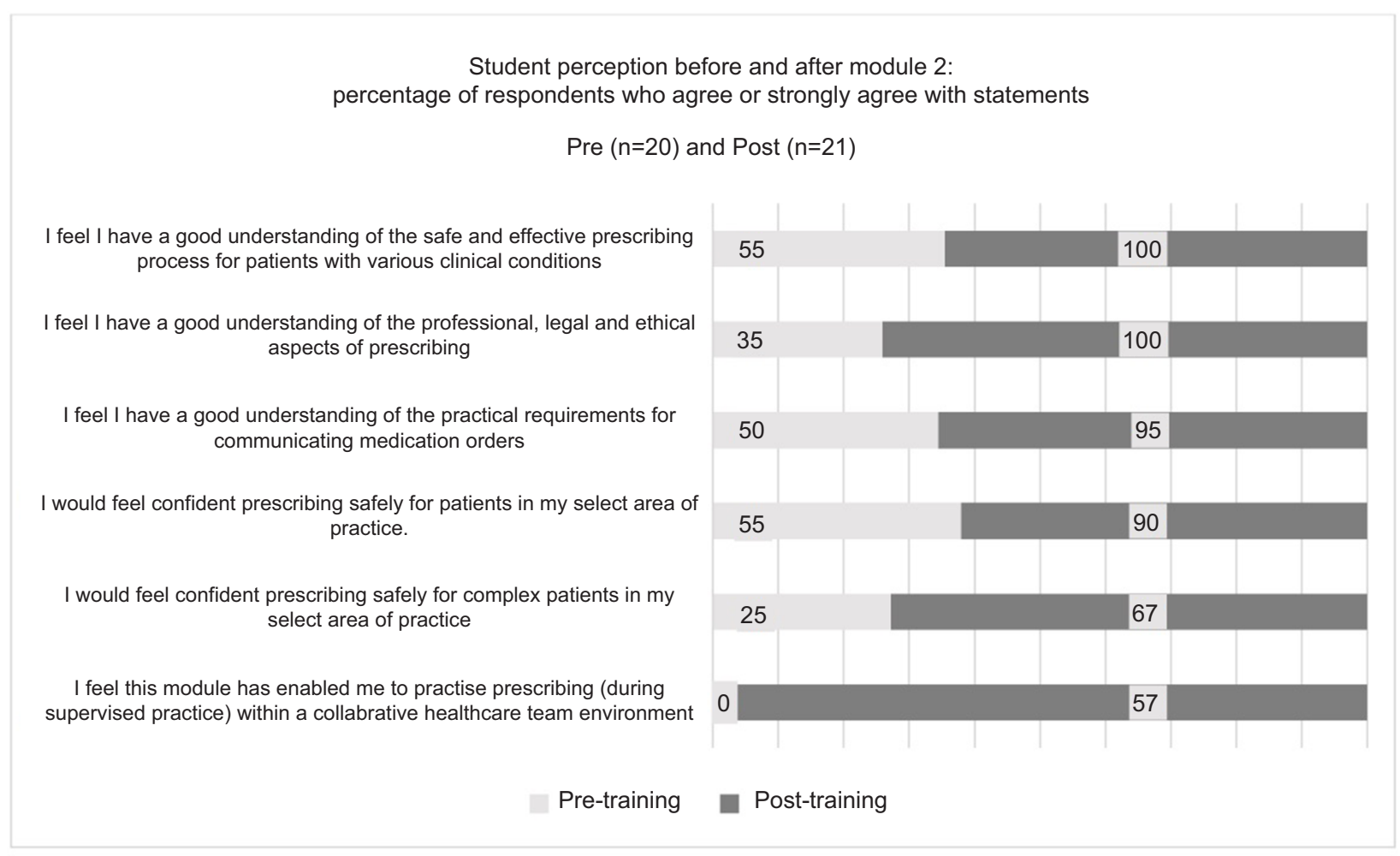

Figure I Understanding and confidence pre/post Module 2.

Table 2 Confidence pre/post 2-day on campus intensive residential

\begin{tabular}{|c|c|c|c|}
\hline $\begin{array}{l}\text { How confident are you to } \\
\text { perform these tasks? }\end{array}$ & $\begin{array}{l}\text { Average score } \\
\text { before residential }^{a} \\
n=23\end{array}$ & $\begin{array}{l}\text { Average score } \\
\text { after residential }^{a} \\
n=22\end{array}$ & Difference \\
\hline $\begin{array}{l}\text { Communicate with patients and/ } \\
\text { or carers to gain complete and } \\
\text { accurate medication history }\end{array}$ & 7.6 & 8.3 & 0.7 \\
\hline $\begin{array}{l}\text { Use of common medical equipment } \\
\text { such as a sphygmomanometer for } \\
\text { taking a patient's blood pressure }\end{array}$ & 3.5 & 5.8 & 2.3 \\
\hline $\begin{array}{l}\text { Identify, analyze, and address a } \\
\text { medical or medication error }\end{array}$ & 6.2 & 7.8 & 1.6 \\
\hline $\begin{array}{l}\text { Resolve an ethical dilemma with a } \\
\text { patient you are reviewing }\end{array}$ & 6.5 & 7.9 & 1.4 \\
\hline
\end{tabular}

Notes: average scores for the entire cohort. Respondents were asked to rate their confidence on a 10 -point scale $(0=$ not at all confident and $10=$ very confident). 
Table 3 Post-program survey: learning in practice

\begin{tabular}{|c|c|c|c|c|c|}
\hline$(n=14)$ & $\begin{array}{l}\text { Strongly } \\
\text { agree (\%) }\end{array}$ & Agree (\%) & $\begin{array}{l}\text { Neither agree } \\
\text { nor disagree (\%) }\end{array}$ & Disagree (\%) & $\begin{array}{l}\text { Strongly } \\
\text { disagree (\%) }\end{array}$ \\
\hline $\begin{array}{l}\text { I feel I have clarity in my future } \\
\text { prescribing role in my area of } \\
\text { practice as a result of LIP }\end{array}$ & 21.4 & 57.1 & 14.3 & 7.1 & 0 \\
\hline $\begin{array}{l}\text { I feel I am confident in my future } \\
\text { prescribing role in my area of } \\
\text { practice as a result of LIP }\end{array}$ & 21.4 & 50.0 & 14.3 & 14.3 & 0 \\
\hline $\begin{array}{l}\text { I feel the QUT AHP training program } \\
\text { adequately prepared me for LIP }\end{array}$ & 0 & 64.3 & 14.3 & 14.3 & 7.1 \\
\hline $\begin{array}{l}\text { I feel I was well supported by my } \\
\text { DMP during LIP }\end{array}$ & 35.7 & 35.7 & 14.3 & 14.3 & 0 \\
\hline $\begin{array}{l}\text { My DMP provided ongoing feedback } \\
\text { in relation to my practice prescribing } \\
\text { during LIP }\end{array}$ & $\begin{array}{l}\text { Yes }-64.3 \% \\
\text { No }-35.7 \%\end{array}$ & & & & \\
\hline
\end{tabular}

Abbreviations: AHP, allied health prescribing; DMP, designated medical practitioner; LIP, learning in practice; QUT, Queensland University of Technology.

(range, 6-12 months; most commonly 7-9 months) was considerably longer than both students and academic staff expected, which remains a consideration for future cohorts and program design.

While not specifically addressed in the surveys completed by participants, anecdotal comments indicated both positive and negative perspectives of the multiprofessional nature of the cohort. During the 2-day on-campus intensive residential, students appeared to appreciate learning from participants of the other profession. However, there were also comments indicating a desire for more profession-specific content in the program. These thoughts are reflected in the following comments:

I think it is great having the physios at the face to face and I learnt a lot from them however, as our skill sets and knowledge bases are so different, the material taught should acknowledge this. [Respondent 12]

The face to face meetings were really good and stimulating, to interact with other allied health prescribers especially of a different discipline. [Respondent 14]

I think there needs to be streams of different education for the different professions (e.g. pharmacists and physiotherapists) as we have quite different needs in relation to prescribing medications. As I see it, physios have a strong patient clinical reasoning differential diagnoses base with needs in prescribing rules, regulations, etc., and pharmacology. Pharmacists have a strong pharmacology base and know a lot about prescribing regulations and may need more patient clinical reasoning education. [Respondent 2]

\section{Discussion}

The essential competencies required to prescribe medicines safely and effectively are articulated for all prescribers in recognized prescribing standards. ${ }^{12,24}$ These standards should scaffold the education and training programs provided for those who will prescribe medicines, regardless of varying profession-specific knowledge and skills and possible prescribing contexts. ${ }^{1,25,26}$ Development of training programs that remain sensitive to these factors while robustly teaching and assessing the core elements of safe prescribing is challenging, yet crucial.

The pre/post Module 2 survey results indicated a positive change in the participants' understanding of and confidence to undertake the prescribing process. At the conclusion of the module, all respondents indicated that they had a good understanding of the process of safe and effective prescribing and an understanding of the professional, ethical, and legal aspects of prescribing. Interestingly, while $90 \%$ of respondents agreed or strongly agreed that they felt confident to prescribe for patients within their area of practice, only $67 \%$ felt confident to prescribe for the more complex patients they might encounter in their area of practice (Figure 1). This may reflect an appropriate level of cautiousness given that prescribing is a new role for these health professionals who lack prior experience in this area of practice.

The residential provided the cohort an opportunity to improve practical prescribing skills. Positive changes were seen in student perception of their confidence to communicate with patients and carers for the purpose of gathering 
an accurate medication history and undertake aspects of the patient assessment process (Table 2). Not surprisingly, physiotherapists felt confident to undertake tasks associated with patient assessment (and the use of medical equipment to support the assessment process) prior to the residential, while pharmacists were less confident with this skill. Overall, pharmacists indicated a higher level of confidence with the task of obtaining an accurate medication history when compared with physiotherapists. Identification of these fundamental differences in the preexisting skills of each profession posed several challenges when designing the program content and particularly the material to support the residential. The practical learning component of the program, however, provided an ideal opportunity to continue to improve skills identified as lacking.

Several points for improvement were identified by the development and coordination team during the delivery of Module 2 and are summarized in the following. Areas for improvement were reinforced by student feedback received in response to the pre/post LIP and pre/post Module 2 surveys. Feedback reflected the constraints placed on the program during this initial offering and highlighted opportunities to improve the content and delivery approach.

A clearer link between Module 1, which focuses on pharmacology and clinical therapeutics, and Module 2 with a focus on safe and effective prescribing and the quality use of medicines may improve the program. In particular, additional specific support for the integration of essential knowledge and practical skill may serve to more concretely embed safe prescribing processes within each individual's practice.

McLellan et $\mathrm{al}^{27}$ describe the need for prescribers to develop prescribing skills in context. The LIP component of the program provided a valuable opportunity to develop and practice prescribing skills in the patient context. However, some students found the unstructured nature of this period of learning difficult to navigate. This finding is consistent with other studies ${ }^{28,29}$ that suggest that detailed instructions regarding how to undertake this vital period of learning are required. The majority of the cohort (71.4\%), however, indicated (agreed/strongly agreed) that the LIP had contributed to their confidence in their future prescribing role.

The assessment of prescribing practices by DMPs may require further development. Specifically, the role and time commitment of the DMP require further clarification, given their valuable contribution to the assessment process. More explicit instructions for the DMP may be useful, for example, what specific aspects of regular work can be included in the LIP supervised hours and the need for the physiotherapist/pharmacist to justify therapeutic decision-making to the DMP as part of the formative and summative assessments. A review of the overall assessment program to further improve the evidence of prescribing ability is warranted.

Program delivery could be improved by allowing Module 2 to be delivered over a longer time period for better consolidation of learning. In this case, the LIP could be run in parallel with the formal teaching period, allowing better integration of learning and practice. However, consideration needs to be given to the routine clinical workload of the participants and university-specific requirements.

The strengths of this training program were that it was designed for a multiprofessional cohort; aligned with national standards for prescribing and core competencies for safe prescribing; delivered by multidisciplinary clinicians, including medical practitioners; and used blended modalities for learning and teaching to reach a cohort dispersed over a large geographical area. This first offering of the program recruited a small number of participants, which limits generalization of the findings. However, some of the learning points may be applicable to other multiprofessional program offerings. Another limitation of the study is that the program was developed and delivered subject to the limited resources available. It is also acknowledged that confidence to prescribe medicines, as investigated in the cohort surveys, does not necessarily equate to effective performance.

\section{Conclusion}

The development of a remote blended learning prescribing training program for a mixed cohort of allied health professionals comprising physiotherapists and pharmacists in a range of health care settings presented both challenges and opportunities for interprofessional teaching and learning. Program delivery, in particular the assessment component, was resource-intensive and relied heavily on information and communication technologies due to the geographical spread of the cohort across the state. The role of the DMP is essential to successful completion of the LIP component and, hence, in the training of a safe and competent prescriber.

\section{Acknowledgments}

The authors would like to thank the 2014/2015 student cohort and acknowledge the contributions of the following to the delivery of Module 2: Unit Co-ordinator, Ms Josephine Martelli, 
Guest Lecturers Dr Alison Mudge, Dr Fiona McDonald, and Ms Deb Lenaghan; Expert Practising Clinician Mr Simon Shah; QUT pharmacy discipline teaching staff (Josephine Martelli, Wendy Thompson, and Hung Tran); and QUT Simulation Centre's nursing staff (Patricia Stickley, Steve Angus, James Parkes, Dennis Cock, and Connie Wishart). The AHPOQ provided funding for student participation in the program. Program content development and delivery were undertaken by QUT.

\section{Disclosure}

The authors report no conflicts of interest in this work.

\section{References}

1. Health Workforce Australia. Health Professionals Prescribing Pathway (HPPP) Project - Final Report. 2013.

2. Nissen L, Kyle G, Stowasser D, Lum E, Jones A, McLean C. Non-Medical Prescribing. An Exploration of Likely Nature of, and Contingencies For, Developing a Nationally Consistent Approach to Prescribing by Non-Medical Health Professionals. Final Report. National Health Workforce Planning \& Research Collaboration; 2010.

3. Weeks G, George J, Maclure K, Stewart D. Non-medical prescribing versus medical prescribing for acute and chronic disease management in primary and secondary care. Cochrane Database Syst Rev. 2016;11:CD011227.

4. Latter S, Smith A, Blenkinsopp A, Nicholls P, Little P, Chapman S. Are nurse and pharmacist independent prescribers making clinically appropriate prescribing decisions? An analysis of consultations. J Health Serv Res Policy. 2012;17(3):149-156.

5. Hale A, Coombes I, Stokes J, Aitken S, Clark F, Nissen L. Patient satisfaction from two studies of collaborative doctor-pharmacist prescribing in Australia. Health Expect. 2016;19(1):49-61.

6. Scobie SD, Lawson M, Cavell G, Taylor K, Jackson SHD, Roberts TE. Meeting the challenge of prescribing and administering medicines safely: structured teaching and assessment for final year medical students. Med Educ. 2003;37(5):434-437.

7. Coombes I, Mitchell C, Stowasser D. Safe medication practice tutorials: a practical approach to preparing prescribers. Clin Teach. 2007;4(3):128-134.

8. Ross S, Loke YK. Development of learning outcomes for an undergraduate prescribing curriculum (British Pharmacological Society prescribing initiative). Br J Clin Pharmacol. 2010;70(4):604-608.

9. Hoti K, Hughes J, Sunderland B. Identifying the perceived training needs for Australian pharmacist prescribers. Int $J$ Pharm Pract. 2014;22(1):38-46.

10. Raghunandan R, Tordoff J, Smith A. Non-medical prescribing in New Zealand: an overview of prescribing rights, service delivery models and training. Ther Adv Drug Saf. 2017;8(11):349-360.

11. Morris JH, Grimmer K. Non-medical prescribing by physiotherapists: issues reported in the current evidence. Man Ther. 2014;19(1): $82-86$.

12. NPS: Better Choices. Better Health. Competencies Required to Prescribe Medicines: Putting Quality Use of Medicines into Practice. Sydney. National Prescribing Service Limited; 2012.

13. Lum E, Mitchell C, Coombes I. The competent prescriber: 12 core competencies for safe prescribing. Aust Prescr. 2013;36(1):13-16.
14. Department of Health. Allied Health Professions' Office of Queensland Department of Health. A Framework for Allied Health Professional Prescribing Trials Within Queensland Health. 2014. Available from: https://www.health.qld.gov.au/_data/assets/pdf_file/0020/158024/ prescribing-fwork.pdf. Accessed May 31, 2014.

15. Robert Gordon University [webpage on the Internet]. Non-Medical Prescribing. Available from: https://www.rgu.ac.uk/study/courses/766non-medical-prescribing-30-credits-level-9-or-30-credits-level-11-ectspoints-15. Accessed May 31, 2014.

16. Keele University [webpage on the Internet]. Independent \& Supplementary Prescribing for Allied Health Professionals. Available from: https://www. keele.ac.uk/health/postgraduate/individualmodules/independentsupplementaryprescribingforalliedhealthprofessionals/. Accessed May 30, 2014.

17. Shaw JP, Print SA, Duffull SB. Development of a postgraduate educational program for pharmacist prescribers in New Zealand. $J$ Pharm Pract Res. 2013;43(2):122-127.

18. The University of Auckland [webpage on the Internet]. Postgraduate Certificate in Clinical Pharmacy in Prescribing. Available from: https://www.fmhs.auckland.ac.nz/en/faculty/for/future-postgraduates/ postgraduate-study-options/programmes/certificates/pgcertclinpharmin-prescribing.html. Accessed June 4, 2014.

19. The University of Otago [webpage on the Internet]. Postgraduate Certificate in Pharmacist Prescribing (PGCertPharmPres). Available from: http://www.otago.ac.nz/courses/qualifications/pgcertpharmpres. html. Accessed June 4, 2014.

20. Robert Gordon University [webpage on the Internet]. Pharmacist Independent Prescribing. Available from: https://www.rgu.ac.uk/study/ courses/880-practice-certificate-pharmacist-independent-prescribing. Accessed June 5, 2014.

21. Keele University [webpage on the Internet]. Certificate in Independent Prescribing. Available from: https://www.keele.ac.uk/study/postgraduatestudy/postgraduatecourses/independentprescribing/. Accessed June 4, 2014.

22. van der Vleuten CP, Schuwirth LW, Scheele F, Driessen EW, Hodges B. The assessment of professional competence: building blocks for theory development. Best Pract Res Clin Obstet Gynaecol. 2010;24(6):703-719.

23. Epstein RM. Assessment in medical education. $N$ Engl J Med. 2007;356:387-396.

24. Royal Pharmaceutical Society. A Competency Framework for all Prescribers. 2016. Available from: https://www.rpharms.com/Portals/0/ RPS\%20document\%20library/Open\%20access/Professional $\% 20$ standards/Prescribing\%20competency\%20framework/prescribingcompetency-framework.pdf. Accessed September 3, 2016.

25. Australian Nursing \& Midwifery Accreditation Council. Nurse practitioner accreditation standards. Australian Nursing and Midwifery Accreditation Council. Canberra: 2015.

26. The Pharmaceutical Journal [webpage on the Internet]. Nursing and Midwifery Council Votes to Adopt RPS Prescribing Competency Framework. 2018. Available from: https://www.pharmaceutical-journal.com/ your-rps/nursing-and-midwifery-council-votes-to-adopt-rps-prescribingcompetency-framework/20204790.article. Accessed May 7, 2018.

27. McLellan L, Tully MP, Dornan T. How could undergraduate education prepare new graduates to be safer prescribers? Br J Clin Pharmacol. 2012;74(4):605-613.

28. Weeks GR, Marriott J, George J. Australian hospital pharmacists' experiences of a UK non-medical prescribing course. $J$ Pharm Pract Res. 2010;40(3):187-193.

29. George J, Bond CM, McCaig DJ, et al. Experiential learning as part of pharmacist supplementary prescribing training: feedback from trainees and their mentors. Ann Pharmacother. 2007;41(6):1031-1038. 
The Journal of Multidisciplinary Healthcare is an international, peerreviewed open-access journal that aims to represent and publish research in healthcare areas delivered by practitioners of different disciplines. This includes studies and reviews conducted by multidisciplinary teams as well as research which evaluates the results or conduct of such teams or health

Submit your manuscript here: https://www.dovepress.com/journal-of-multidisciplinary-healthcare-journa

care processes in general. The journal covers a very wide range of areas and welcomes submissions from practitioners at all levels, from all over the world. The manuscript management system is completely online and includes a very quick and fair peer-review system. Visit http://www.dovepress.com/ testimonials.php to read real quotes from published authors. 